INFORMACIÓN

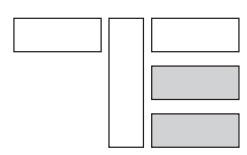





\section{SEMINARIO INTERUNIVERSITARIO DE TEORÍA DE LA EDUCACIÓN}

\section{LECTURA Y EDUCACIÓN}

Lloret de Mar (Girona), 12 a 14 de noviembre de 2007 Universitat Autònoma de Barcelona

En esta ocasión, las tranquilas aguas del Mediterráneo han sido cómplices de nuestro encuentro anual. Concretamente, el eje temático abordó el sugerente enlace entre lectura y educación. Como sabemos, los seres humanos no tenemos posibilidad extracultural. Por ello, algunas culturas (no todas) han desarrollado su forma de ser a través de lo gráfico. Una condición que entronca, obviamente, con la facultad de leer. He aquí un binomio indisoluble: escritura y lectura.

Bajo este contexto, una nutrida representación de profesores y profesoras de Teoría de la Educación, llegados de distintas universidades españolas, trabajaron la cuestión. En este sentido, cuatro ponencias se tomaron como leitmotiv: a) Aspectos cognitivos de la lectura, b) La lectura como experiencia humana, c) La lectura en el siglo XXI y d) Lectura y género: leyendo la invisibilidad.

Además, un conjunto de cuarenta adendas perfilaron el resto del estudio. La novedad, en forma de contrapunto, fue externa. Para esta edición, se invitó a insignes lectores (Octavi Fullat, Antonio Rodríguez y Emili Teixidor) que alentaron un vivo debate entre la concurrencia.

Referente a los objetivos, éstos fueron los siguientes:

- Tramar los límites y retos de la dimensión cognitiva en la lectura.

- Abordar la lectura desde voces antropológicas centradas en elementos experienciales.

- Profundizar en la relación entre la lectura y las nuevas tecnologías.

- Contextualizar la especificidad de cada género en la lectura.

Sin duda, la importancia del tema debe implicar una atención, extensa e intensa, por parte de cualquier profesional educativo. Asimismo, debemos recordar que periódicamente el informe PISA evalúa esta actividad entre nuestro alumnado de quince años.

Por último, todos los trabajos han sido publicados en AsEnsio, J. M. et al. (2008) Actas del XXVI Seminario Interuniversitario de Teoría de la Educación. Lectura y educación. Barcelona, Universitat Autònoma de Barcelona, http://www.ucm.es /info/site/docu/26site/actas26site.pdf. 